\title{
Perceptions of vocabulary teaching methods among EFL teachers
}

Bouirane, Ahlam $\bowtie$

Mohamed Lamine Dabaghine University Sétif 2, Algeria (b.ahlam@outlook.com)

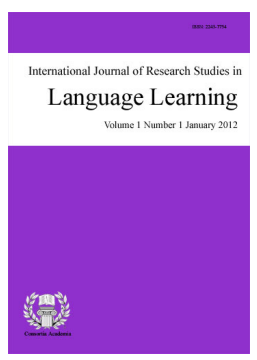

ISSN: 2243-7754

Accepted: 2 February 2016 Online ISSN: 2243-7762

OPEN ACCESS

\section{Abstract}

This paper investigates the perceptions of EFL teachers towards vocabulary teaching in the EFL classroom. The participants in this study are three oral expression teachers and 32 teachers at the English Language and Literature Department at Mohamed Lamine Dabaghine University, Sétif 2-Algeria. The research follows a quantitative and a qualitative design that uses a questionnaire and an observation respectively to answer its questions. The questionnaire collected the perceptions of the participants about their vocabulary teaching method. The observation phase was conducted to compare the responses of the observed participants with their actual classroom teaching methods. Analysis of the questionnaire data revealed that the teacher participants have a low perception of vocabulary teaching methods. Moreover, analysis of the obtained results from the observation revealed low vocabulary methods teaching perceptions and lack of awareness among the teachers in terms of vocabulary teaching methods use.

Keywords: English as a Foreign Language; vocabulary; vocabulary teaching methods; perceptions; teacher awareness 


\section{Perceptions of vocabulary teaching methods among EFL teachers}

\section{Introduction}

As a research area, vocabulary was neglected for years in second and foreign language studies. In recent years, Vocabulary started to get more importance and focus as indicated by the increase in the number of publications and researches related to the study of lexicon in the context of second and foreign language studies. While Grammar was the focal study area for second language research up to the 1980s, vocabulary "has mushroomed enormously" (Meara, 1995, p. 11), and turned to be the center of research in the last three decades. This progress has settled vocabulary in the core of emerging theories where "vocabulary knowledge is indispensable to acquire grammar" (Malvern et al., 2008, p. 270), as stated in the theoretical tenets of the Lexical Learning Hypothesis. The wealth of existing language teaching approaches and methods has tackled vocabulary differently in relation to their basic tenets (Richards \& Rodgers, 2001). Although vocabulary research did not bloom until very recently, the importance of vocabulary was recognized within the heydays of most language teaching methods.

\section{Literature Review}

Vocabulary teaching is one of the most important elements in the language classroom because it helps learners to express their ideas and feelings through words and meanings. As important as language structures are for language being its skeleton, so is vocabulary which provides the vital organs and flesh (harmer, 1993: 153). The importance of vocabulary learning to learn a language is widely accepted, and the role vocabulary has in receptive and productive language situations, has also been proved throughout the research literature. According to Laufer (1997, p. 147):

Vocabulary is no longer a victim of discrimination in second language learning research, nor in language teaching. After decades of neglect, lexis is now recognized as central to any language acquisition process, native or non-native. What many language teachers might have intuitively known for a long time, that a solid vocabulary is necessary in every stage of language learning, is now being openly stated by some second language acquisition (SLA) researchers.

There is no doubt that second and/or foreign language practices have undergone through considerable developmental stages that produced different trends. Recognized in this evolution is the focus on vocabulary as a main language component after decades of neglect.

In response to the growing interest in vocabulary teaching and learning, new approaches have been suggested to meet the findings of vocabulary research, and to provide teachers with a wealth of vocabulary teaching approaches, such as discourse-based language teaching (Carter \& McCarthy, 1988), the lexical phrase approach (Nattinger \& DeCarrico, 1992), the lexical approach (Lewis, 1993, 1997), and the lexical syllabus (Sinclair \& Renouf, 1988; Willis, 1990). Vocabulary learning research can reciprocally affect L2 learning and teaching. Since vocabulary development is "arguably central to language acquisition and use" (Zimmerman, 1997, p. 17), the use of effective vocabulary instruction methods is highly required.

Teachers are viewed as main resources in the language classroom through directing the attention of their learners to specific information that help in developing their cognitive processes and transmitting the output into input successfully (Newton, 2001; Schank, 1999; Skehan, 1998). Vocabulary research has not reached a unified view on the efficacy of one particular instruction method over another as Beck, McKeown and Omanson (1987, p. 150) argue, "Research has provided much useful information about vocabulary learning and instruction. What it has not provided is a simple formula for optimal instruction, because no such formula can exist". However, there is a strong debate about whether explicit or implicit instruction should be used for effective vocabulary 
learning.

Many researchers (Cunningham, 2005; Hiebert \& Kamil, 2005; Nagy, 2005; Skehan, 1998; Stahl, 2005) opted for a direct, systematic, multifaceted instruction with room for multiple exposures, in order to promote word knowledge as well as its different aspects. Explicit vocabulary learning guides the attention of the learners to vocabulary, through their direct involvement in activities that focus primarily on vocabulary. Teaching vocabulary explicitly uses a variety of techniques including word definitions, synonym pairs, word lists, word associations, the keyword method, semantic mapping and semantic feature analysis (Duin \& Graves, 1987). Other techniques include the use of realia, pictures, mimicry, explanation, and translation (Harmer, 1991). For example, to explain the efficiency of word association in developing learners' vocabulary, Sokmen (1997, pp. 241-242) indicates that

The human lexicon is believed to be a network of associations, a web-like structure of interconnected links. When students are asked to manipulate words, relate them to other words and to their own experiences, and then to justify their choices, these word associations are reinforced.

Nation (2001) divides words into low frequency and high frequency words, for which non-native speakers need to master the latter first, since it is limited in size and relatively deserving time and attention. Besides, Nation (2001) argues that teaching second language vocabulary explicitly may raise the learners' awareness about the words they learn and facilitate their recognition in later stages of learning. He clarifies this argument stating:

When words are met in reading and listening or used in speaking and writing, the generativeness of the context will influence learning. That is, if the words occur in new sentence contexts in the reading text, learning will be helped. Similarly, having to use the word to say new things will add to learning” (Nation 2001, p. 80).

Schmitt (2000) also supports the beneficial role of direct instruction, stating that learners can learn large quantities of vocabulary through the use of word lists for example. He further explains,

The more one manipulates, thinks about, and uses mental information, the more likely it is that one will retain that information. In the case of vocabulary, the more one engages with a word (deeper processing), the more likely the word will be remembered for later use (p. 120).

The same position is held by Oxford and Scarcella (1994) who insisted on the necessity of explicit vocabulary instruction in leading the learners to develop vocabulary learning strategies inside and outside the classroom. Schmitt and Carter (2000, p. 4) further claim that "Due to the incremental nature of vocabulary acquisition, repeated exposures are necessary to consolidate a new word in the learner's mind".

These teaching techniques and the whole explicit vocabulary learning method were severely criticized for the major factor of vocabulary being too broad to be covered and learned through explicit backgrounds (Nagy, 1997). The alternative for this explicit vocabulary instruction was to teach vocabulary implicitly. The aim of indirect vocabulary instruction is to draw the attention of the learners to the target words, which will be grasped "incidentally" through exposure to a variety of contexts, reading and materials with the focus on language use instead of learning itself. Research indicates that this unplanned vocabulary learning goes true for the low frequency words for which the learners are exposed to in various contexts, so they do not necessitate a direct instruction. In this implicit method of vocabulary teaching, Nation and Newton (1997, p. 238) point out that "...the teacher needs to ensure that learners are being exposed to materials and activities that will expand their vocabulary in useful ways".

Hence, the role of the teacher under implicit vocabulary teaching is to guide the learners and draw their attention through more reading and various types of activities. Sökmen (1997) specified three methods to teach 
vocabulary implicitly. First, teachers should guide learners to establish links between words to learn and words already learnt, because "the human lexicon is, therefore, believed to be a network of associations, a web-like structure of interconnected links" (Sökmen, 1997, p. 241). Second, teachers should focus on recalling words through longer intervals rehearsal opportunities. Finally, teachers need to use effective materials for illustration and rely on real life contexts. All in all, the implicit instruction requires rich contexts and multiple exposures to the target words to learn new vocabulary items (Nation, 2001).

The debate among researchers as to the efficiency of explicit and implicit vocabulary teaching was not settled, and pushed researchers to suggest more detailed methods. Seal (1991), for instance, classified vocabulary teaching strategies into planned and unplanned activities in the classroom. While unplanned strategies refer to incidental or implicit vocabulary learning, and planned vocabulary teaching refers to explicit instruction, the three main stages of conveying meaning, checking retention, and consolidation of meaning are followed to put both strategies into practice.

Oxford and Crockall (1990) proposed another detailed analysis of vocabulary teaching methods with a four categories classification (1) de-contextualising: the words are presented in isolated forms such as word lists, flashcards, and dictionary use; (2) semi-contextualising: there exists some kind of context to present vocabulary, such as word grouping, association, visual imagery, aural imaginary, keyword, physical response, physical sensation, and semantic mapping; (3) fully contextualizing that involves the use of context to present vocabulary mainly through reading, listening, speaking, and writing; (4) adaptable which supplement all the other techniques.

Another taxonomy that classifies vocabulary instruction approaches was provided by Hunt and Beglar (1998) based on a three approaches modality of: incidental vocabulary learning through receptive skills, direct instruction through explicitly drawing the attention of learners to target words to be learnt, and independent strategy development which incorporates total reliance on context to guess words and meanings.

\subsection{Statement of the Problem}

The importance of vocabulary as a research area does not state for granted that teachers are aware of the various methods of vocabulary teaching available in the literature. Although research has emphasized that vocabulary is the skeleton of language and its building block, teachers may not be aware of the various ways to teach vocabulary. Hence, there is a need to ask teachers as main vocabulary resources in the EFL classroom, about their perceptions of vocabulary as language sub-skill and the vocabulary teaching and methods they use. The problem stated for the context of the present study is the lack of teacher awareness of the plethora of vocabulary teaching methods.

\subsection{Research Questions}

The current research seeks to answer the following research questions:

$>\quad$ How do EFL teachers perceive vocabulary teaching?

$>\quad$ To what extent are EFL teachers aware of their vocabulary teaching methods?

\subsection{Aims of the Study}

The main motif behind the present study is to explore the degree of awareness of EFL teachers at the English Language and Literature Department at Sétif 2 University of vocabulary teaching methods. The study also aims at describing the method (s) of vocabulary teaching in the oral expression classroom as a space devoted for teaching vocabulary per se. Last but not least, the research aspires to raise teachers' awareness about aspects related to vocabulary teaching methods. 


\section{Methodology and Research Design}

The current study uses both a qualitative and quantitative research design to gather data. After administering the questionnaire as a main data collection instrument to the whole population of teachers to collect their perceptions of vocabulary teaching methods, a non- participant observation was carried. The aim of the observation was to survey the methodology and the types of activities that teachers use to teach vocabulary in the oral expression classroom. Upon analysis of the observation, a questionnaire was administered to the three observed teachers to compare their observed teaching method with their questionnaire responses.

\subsection{Participants}

The participants in the current research included 35 teachers of English as a foreign language at the English language and Literature Department at Mohamed Lamine Dabaghine University Sétif 2- Algeria.

Oral Expression Teacher participants - The oral expression teacher participants in the current study are three purposively selected teachers teaching third year students at the Department of English Language and Literature, Mohamed Lamine Dabaghine University Sétif 2, Algeria. Two female teachers and a male teacher share the responsibility of teaching 380 students divided into 11 groups. Oral expression module is a three hours weekly session introduced as a one hour and a half session at the language laboratory and another at the classroom. The teachers were purposively selected because they present different age, academic, and experience background levels. Further details about the oral expression teacher participants are provided in profiles below (see data analysis section).

Teacher Participants - The teacher participants in this study involved 32 teachers out of 53 teachers at the English Language and Literature Department at Mohamed Lamine Dabaghine University Sétif 2, Algeria. They were 10 male and 22 female teachers and have an English teaching experience of 4 to 28 years. The participants were teaching a variety of modules presenting various levels of students including first, second, and third year bachelor level to first and second year masters level. The teachers were selected randomly to present all levels and modules in order to cover the teaching and assessment of vocabulary methods use in the department.

\subsection{Research Instruments}

The study used observation as a qualitative data collection tool and a questionnaire as a quantitative data collection tool.

The Questionnaire - Designed to collect data about the perceptions of teachers towards their vocabulary teaching practices in the classroom, the Vocabulary Teaching Methods Questionnaire (VTMQ) was the main data collection instrument. It included seven questions mostly in multiple choice formats to cover most of the teaching and assessment methods of vocabulary.

The Observation - The observation phase was conducted to gather insights about the current situation of vocabulary teaching in third year oral expression classrooms. The choice of the module of oral expression stemmed from its focus on teaching vocabulary per se if compared to other modules in which vocabulary is a vehicle to convey information or integrated within other language skills. The researcher carried a non-participant observation with a random sample of three third year classes belonging to three different teachers who teach oral expression for all third year population. Using a five-scale checklist (Not Observed, Need Improvements, observed, and shown very well), the researcher collected specific data relevant to the research context. The observation focused on the main aspects of teaching content and vocabulary load, vocabulary learning activities, vocabulary instructional method, and vocabulary assessment method. 


\subsection{Data Collection Procedures}

The Questionnaire - To overcome any ambiguities or difficulties in understanding and responding to the statements and questions of the VTMQ, a piloting phase was conducted. The VTMQ was piloted twice with a sample of 7 teachers non-included in the overall study sample. The reflections gained from the responses of the first piloting helped the researcher restructure the questionnaire to cover a wider range of teaching and assessment methods. In the second piloting, the 7 teachers responded again to the restructured questionnaire with no difficulties. Hence, the researcher administered the final VTMQ to the teacher participants after stating the problem and aim of the study. Generally speaking, teachers reflected considerably on the questions to link the answer choices to their classroom practices.

The observation - Selected to collect data from within the classroom, the observation phase provided data about the vocabulary teaching method in third year oral expression classrooms. Three randomly selected third year groups belonging to three different teachers responsible for teaching oral expression to the whole population of third year students were subject for five observation sessions of three hours each. Hence, the observation lasted for fifteen hours for each group both at the language laboratory and the classroom. The observation started on January $4^{\text {th }} 2015$ and ended on February $8^{\text {th }} 2015$. An observation checklist was used to follow the availability or otherwise not of the research focused on elements.

\subsection{Data Analysis Procedures}

The data gathered by means of the questionnaire were analyzed using the SPSS 22.0 software (2014). The software analyzed the obtained data to verify the questionnaire reliability. The alpha coefficient for the reliability of teachers' questionnaire across all the teachers was .78 (Cronbach alpha $=.78$ ). This alpha coefficient result reports a high reliability in excess of .70 (Dornyei, 2003). Then, frequencies and chi-square differences were calculated for the data obtained.

The data collected during the observation stage were analyzed qualitatively to report on the way teachers teach and assess vocabulary in their classrooms. The data were organized into profiles to respond to the three observed classrooms and teachers. Moreover, the researcher used an observation evaluation checklist to analyze and interpret the obtained data.

\section{Results and Discussion}

\subsection{Research Question 1}

To answer the first research question, the VTMQ provided quantitative data in the form of frequencies. The teachers estimated the importance of vocabulary to be ranging between important $(50.0 \%)$ and very important $(46.9 \%)$ to convey the content of their modules as shown in table 1 below:

\section{Table 1}

Teacher Participants' Perceptions of vocabulary importance

\begin{tabular}{lcccc}
\hline \multicolumn{1}{c}{ Option } & Frequency & Chi-square & $d f$ & Asymp.sig \\
\hline Not important & 3.1 & & & \\
Important & 50.0 & 13.18 & 2 & .001 \\
Very important & 46.9 & & & \\
Total & 100.0 & & \\
\hline Note. *Decision taken about the significance of the results at the degree of freedom (2) and significance level 0.05
\end{tabular}

As most teachers use vocabulary as a means to introduce the knowledge relevant to the subject areas they teach, the importance of vocabulary depends on the nature of the module itself. Many scholars (Ellis, 1994; Lewis, 1993; Nandy, 1994; Zimmerman, 1997) emphasized the importance of vocabulary in language teaching. 
Consequently, the teacher participants have a high perception of vocabulary as an important language element as confirmed by the .001 significance result which is below the 0.05 significance level.

Concerning setting objectives, 13 teachers (40.6\%) among the 32 teachers stated that they set objectives to teach vocabulary per se in their lesson plans as shown in table 2 below:

Table 2

Teacher Participants' Vocabulary Objectives Setting

\begin{tabular}{|c|c|c|c|c|}
\hline Option & Frequency & Chi-square & $d f$ & Asymp.sig \\
\hline Yes & 40.6 & & & \\
\hline No & 59.4 & 1.12 & 1 & .28 \\
\hline Total & 100.0 & & & \\
\hline
\end{tabular}

Setting objectives assist in directing the attention of learners to specific information that helps in developing their cognitive processes and transmitting the output into input successfully (Newton, 2001; Schank, 1999; Skehan, 1998). Hence, the majority of teachers reported that they do not set objectives specifically to teach vocabulary. This implies that teachers have a low perception of setting objectives for vocabulary learning. This is further confirmed by the significance result of .28 which is beyond 0.05 .

In order to specify the overall objective behind teaching vocabulary, teachers stated that they aim to achieve a mixture of purposes as shown in table 3 below:

\section{Table 3}

Teacher Participants' Perception of Vocabulary Teaching Purposes

\begin{tabular}{lcccc}
\hline \multicolumn{1}{c}{ Option } & Frequency & Chi-square & $d f$ & Asymp.sig \\
\hline Promoting VK & 28.1 & & & \\
Developing VLS & 15.6 & 5.50 & 4 & .240 \\
Providing VLR & 9.4 & & & \\
All of them & 31.3 & & & \\
Other purposes & 15.6 & 100.0 & & \\
Total & Note. *Decision taken about the significance of the results at the degree of freedom (2) and significance level 0.05
\end{tabular}

The majority of teachers $(31.3 \%)$ stated that they teach vocabulary to develop learner's vocabulary knowledge (VK) and vocabulary learning strategies (VLS), as well as to provide vocabulary learning resources. Teachers further pointed out that promoting VK constitutes a priority for them. This tendency reflects teachers' awareness of the importance of vocabulary knowledge and its role in establishing successful learning (McCarthy, 1990; Read, 2000). The result is not significant and state a low perception of vocabulary teaching purposes as the chi-square and the significance result which is beyond 0.05 indicate.

Selecting activities is also a main part in lesson planning. In fact, the types of modules that teachers teach determined the use or otherwise not of activities in the classroom. Table 4 below states the use of vocabulary learning activities according to modules:

\section{Table 4}

Teacher Participants' Perception of Vocabulary Activities selection

\begin{tabular}{|c|c|c|c|c|}
\hline Option & Frequency & Chi-square & $d f$ & Asymp.sig \\
\hline Yes & 56.3 & & & \\
\hline No & 43.8 & .50 & 1 & .48 \\
\hline Total & 100.0 & & & \\
\hline
\end{tabular}

Most teachers (56.3\%) stated that they do not select activities to teach vocabulary. This implies that they do 
not perceive vocabulary activities as a main component in vocabulary teaching as stated by the .48 significance which is beyond the 0.05 significance level. This does not deny the role of vocabulary but gives more importance to providing information and knowledge relevant to the module. As a language component, vocabulary does not import its importance to serve its own sphere; rather it spreads to affect the four language skills through integration. Lessard-Clouston (1996, p. 27) affirms "Vocabulary - words, phrases, idioms, etc. is at the heart of all language usage in the skill areas of listening, speaking, reading, and writing, as well as culture." This importance rises from the roles vocabulary plays in many respects.

Because teachers reported that they do not select activities, the types of activities were also reported to be of limited use and variety as shown in table.5 below:

\section{Table 5}

Teacher Participants' Perception of Vocabulary Activities use

\begin{tabular}{|c|c|c|c|c|c|}
\hline Option & & Frequency & Chi-square & $d f$ & Asymp.sig \\
\hline Provide definitions & & 12.5 & \multirow{13}{*}{19} & \multirow{13}{*}{11} & \multirow{13}{*}{0.61} \\
\hline sentence completion & & 2.8 & & & \\
\hline Reading activities & & 6.9 & & & \\
\hline Listening activities & & 8.3 & & & \\
\hline Speaking activities & & 5.6 & & & \\
\hline Writing activities & & 11.1 & & & \\
\hline Provide synonyms/antonyms & & 15.3 & & & \\
\hline \multicolumn{3}{|l|}{ Matching activities } & & & \\
\hline Use new words in context & & 11.1 & & & \\
\hline Use context to draw meaning & & 9.7 & & & \\
\hline All of them & & 4.2 & & & \\
\hline \multirow[t]{2}{*}{ Others } & & 1.4 & & & \\
\hline & Total & 100.0 & & & \\
\hline
\end{tabular}

Note. ${ }^{*}$ Decision taken about the significance of the results at the degree of freedom (2) and significance level 0.05

Providing definitions (12.5\%), synonyms and antonyms (15.3\%) activities were reported to be the highly frequently used activities, and these activities characterize explicit vocabulary teaching (Duin \& Graves, 1987; Sokeman, 1997; Nation, 2001; Schmitt, 2000; Oxford \& Scarcella, 1994; Schmitt \& Carter, 2000). Likewise, writing activities and using context to teach vocabulary activities were also significantly reported to be used frequently (11.1\%) reflecting explicit vocabulary teaching (Nagy, 1997; Nation \& Newton, Sokeman, 1997). While the majority of teachers stated that they do not use vocabulary learning activities at all to teach vocabulary as shown in table 4, they reported to use a variety of vocabulary activities types. Overall, the teachers did not report positive perceptions for using vocabulary learning activities as stated by the 0.61 significance of the results which is beyond 0.05 .

Both aspects of vocabulary activities use and their types are dependent on the vocabulary teaching method used. Therefore, the majority of teachers opted for using the four skills (listening, speaking, reading, and writing) to create contexts for vocabulary use. Table 6 below summarizes the frequency of vocabulary teaching methods used:

Table 6

Teacher Participants perceptions of deductive vocabulary teaching methods

\begin{tabular}{|c|c|c|c|c|}
\hline Option & Frequency & Chi-square & $d f$ & Asymp.sig \\
\hline De-contextualizing & 19.0 & \multirow{6}{*}{8.93} & \multirow{6}{*}{4} & \multirow{6}{*}{0.63} \\
\hline Semi-contextualizing & 28.6 & & & \\
\hline Fully-contextualizing & 35.7 & & & \\
\hline Structured reviewing & 14.3 & & & \\
\hline Others & 2.4 & & & \\
\hline Total & 100.0 & & & \\
\hline
\end{tabular}


Teaching vocabulary through its integration in other language skills confirms the tendency of teaching vocabulary according to the requirements of the modules as shown in table 3 above. The participants have a low perception of their explicit vocabulary teaching method as the 0.63 significance result confirms. Moreover, when asked about their vocabulary teaching method, teachers stated both explicit and implicit methods, as shown in table 6 below:

\title{
Table 6
}

Teacher Participants' perceptions of vocabulary teaching methods

\begin{tabular}{|c|c|c|c|c|}
\hline Option & Frequency & Chi-square & $d f$ & Asymp.sig \\
\hline Deductive/explicit teaching & 59.4 & & & \\
\hline Inductive/implicit teaching & 40.6 & 1.000 & 2 & 0.60 \\
\hline Total & 100.0 & & & \\
\hline
\end{tabular}

Fully-contextualizing stands for implicit integration of vocabulary in the four language skills (Oxford and Scarcella, 1994). Hence, teachers use vocabulary as a means to convey knowledge relevant to the subject while vocabulary learning happens incidentally (Nagy, 1997; Sökmen, 1997). Teachers showed lack of awareness about the distinction between implicit and explicit vocabulary teaching as reported from table 5 and 6 results. The significance level of 0.60 which is beyond 0.05 further confirms the low perception about vocabulary teaching method among the participants.

\subsection{Research Question 2}

To answer the second research question, the observation was the main tool used to collect data. The aim was to report the actual practices of oral expression teachers in terms of vocabulary teaching and assessment in the classroom. The observation data were compared with the VTMQ questionnaire answers of the observed teachers. The researcher organized the obtained data from the observation and the questionnaire in the form of profiles.

\section{Profile of Teacher One}

\author{
Gender: Male \\ Degree Held: Magister \\ English Teaching Experience: 26 years \\ Oral Expression teaching experience: 19 years \\ Lesson opening: presentation \\ Lesson development: presentation and discussion \\ Lesson closing: discussion
}

Types of vocabulary activities: whole class oral discussion activity

Teacher use of language: questions, definitions, synonyms, antonyms, examples, keywords, use new words in context.

Vocabulary teaching method: deductive fully contextualizing

Type of vocabulary knowledge emphasized: receptive knowledge (listening)

Purpose of vocabulary teaching: promoting the vocabulary knowledge, development of vocabulary learning strategies, providing resources for English vocabulary learning

The first teacher observed had an overall experience of 19 years in teaching oral expression. This experience enabled him to deal with teaching vocabulary thematically to meet students' needs. His vocabulary teaching was deductive through discussions and no room for vocabulary activities use. In the language laboratory, the teacher introduced the students into English language varieties (British, American, Australian, and South African) through videos, broadcasts and recordings. Moreover, the vocabulary presented was thematic reflecting cultural and authentic contexts. Themes such as politics, domestic violence, climate change, Britain's child beggars, multiculturalism, and human trafficking were dealt with through discussions. In addition, the teacher created links between the previously stated information and the new content. The vocabulary load was appropriate to the level of the students since the teacher diversified the contexts. Hence, the students react to the theme first at the 
laboratory in response to the questions of the teacher. Later in the classroom, the students discussed the theme in broader terms under the full guidance of the teacher.

However, the variety of themes presented was opposed to the use of the same method of vocabulary teaching. The observed teacher used the same pattern of teaching vocabulary that focused on the presentation and discussion stages. The overall teaching method started with the teacher presenting the theme to the students through a listening task (listening to broadcast, speech, or watching a video). After the listening section, the teacher opened a discussion about the theme with the students to draw their reflections on what they had listened to. Meanwhile, the whole discussion was teacher-dominated with few interaction and discussion opportunities created for students. This low student interaction could be the result of little background knowledge about the theme and the one-listening to the theme opportunity offered. Moreover, there are no opportunities for vocabulary practice since there was no vocabulary activities presented and the whole stages of practice and production were totally missing. The teacher did not encourage the use of the dictionary and relied on spelling to introduce new words instead of using the white board. Overall, the teaching method was fully a one stage teacher presentation-based.

The comparison of the observation results with the teacher questionnaire answers revealed a lack of awareness of the variety of vocabulary teaching methods. The teacher stated in the questionnaire that vocabulary teaching is very important, and this was felt and observed in the classroom. Additionally, the teacher stated that his aims of teaching vocabulary cover the aims stated in the questionnaire and the observation confirmed his answer. Yet, he did not neither provide the objectives nor discuss their attainment or otherwise not at the end of the session with his students. The teacher response to the use of vocabulary learning activities further confirmed his teaching method which lacks practice. In fact, even the types of activities the teacher reported to use in the questionnaire were teacher-handled since the students have no chances for practice.

In the questionnaire, the teacher pointed out that he uses a fully-contextualizing method of vocabulary teaching. However, the observation reports that only listening and speaking skills are reinforced with intensive focus on listening and receptive vocabulary. The overuse of the same method of presenting vocabulary which builds on presentation and discussion with total neglect of practice and few opportunities for students' spoken production emerge from the lack of awareness about vocabulary teaching methods. Besides, the focus on receptive vocabulary teaching through listening to selected instructional materials or the teacher himself limited the students' resources.

\title{
Profile of Teacher Two
}

\author{
Gender: Female \\ Degree held: bachelor \\ English teaching experience: 11 years \\ Oral expression experience: 10 years \\ Lesson opening: presentation \\ Lesson development: practice \\ Lesson closing: practice
}

Types of vocabulary activities: providing definitions, synonyms/antonyms activity, matching activities, language games, fill-in the gaps, sentence completion

Teacher use of language: questions, definitions, examples, prompt instructions, synonyms, antonyms, keywords.

Vocabulary teaching method: deductive semi-contextualizing

Type of vocabulary knowledge emphasized: productive (speaking)

Purpose of vocabulary teaching: promoting vocabulary knowledge of learners

In the second classroom observed, the teacher has ten years' experience in teaching oral expression. Although her vocabulary teaching method was also deductive and theme discussion-based as the first teacher, the themes included were of less variety. However, practice was not neglected if compared to the first teacher. At the presentation stage, the teacher introduced the theme briefly to the students through brainstorming. Then the 
themes were wholly presented through a listening task in which videos and broadcasts were used in the language laboratory. In the classroom, the teacher discussed the theme with the students through questions. Then, the students practice the presented vocabulary through a series of activities. The production stage was neglected within the lesson stages, but was considered as an assessment tool in which students have to prepare projects on assigned topics and present them.

The vocabulary presented was thematic and practical reflecting authentic contexts of use, but there was no continuity between previous and new presented information. Every session contents and vocabulary stood isolated from the next content provided. The vocabulary load was adequate to the level of the intended students, but the content and situations were less stimulating of new themes. The vocabulary learning activities used were level appropriate creating opportunities for vocabulary knowledge use and for classroom participation. Moreover, there were smooth links between the activities since the students move from a recognition stage to use in assigned situation. Moreover, there was a variety in the types of activities used too, as stated in the teacher profile, since practice was the main stage of the lesson. The teacher-students interaction was remarkable with many opportunities for students to discuss and speak and the teacher was mostly and instructor and guide.

Comparing the observed data with the responses of the teacher to the VTAMQ indicates some contradictions between the real classroom performance of the teacher and her answers to the questionnaire. This contradiction resulted from the lack of awareness about vocabulary teaching and assessment methods. While the teacher stated in the questionnaire that teaching vocabulary is very important which was witnessed in the classroom, the vocabulary teaching and assessment methods reported to be used did not cope with the observed methods in the classroom. Similar to first teacher, the second teacher stated in the questionnaire that she sets objectives for teaching vocabulary; these objectives were not provided at the beginning or checked for attainment at the end of the session. Besides, some types of activities reported to be used in the questionnaire such as using new words in context, using context to draw meaning, and listening were not observed in the classroom. In fact, the listening task was provided as a presentation stage rather than practice through listening activities.

In responding to vocabulary teaching methods, the teacher stated that she follows a semi-contextualizing method which contradicts with what was observed in the classroom. The teacher used a deductive structured reviewing vocabulary teaching method. De-contextualizing could be explained by her using word lists in the form of phrasal verbs and idiomatic expressions, and encouraging dictionary use. Semi-contextualizing appeared in her use of word grouping and visual imagery. And fully-contextualizing was observed in the listening and speaking tasks. Moreover, the emphasis on practice as the main stage the students' intensive discussion of the theme encouraged productive vocabulary use situations to meet the teacher's objective of promoting the students' vocabulary knowledge.

\section{Profile of Teacher Three}

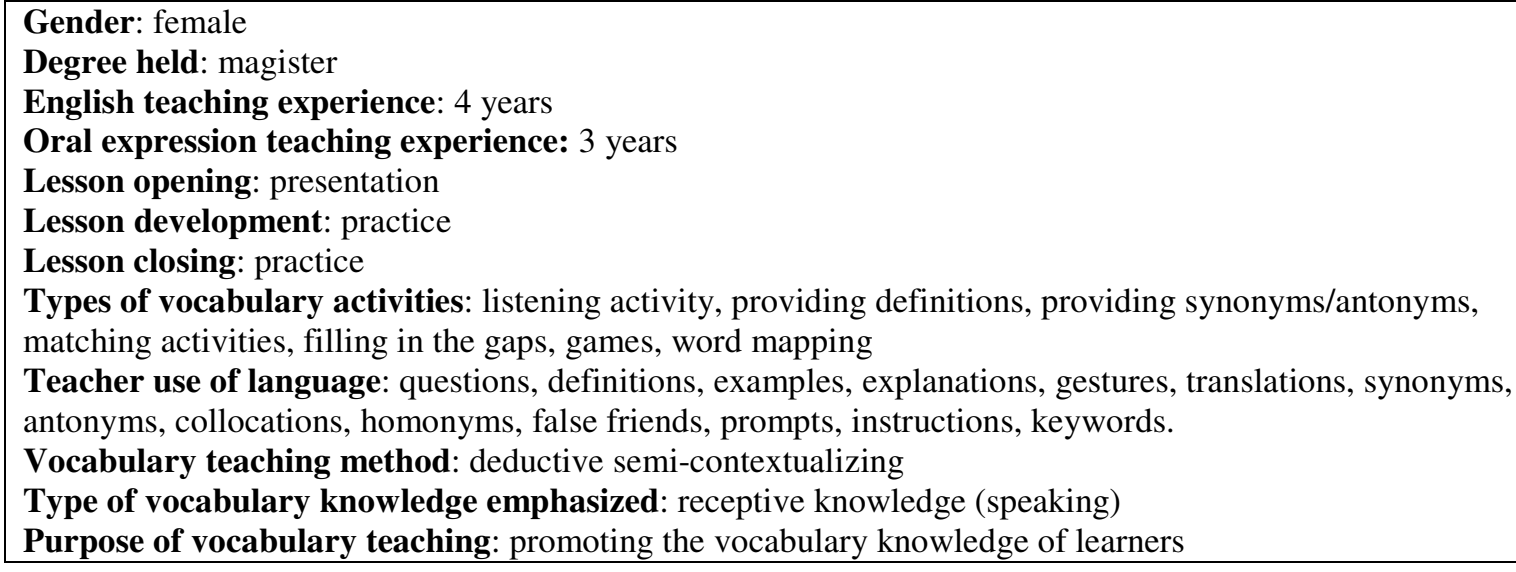

The third teacher was the youngest and less experienced compared to the previously stated teachers. The 
vocabulary was presented deductively but of less thematic variety and context authenticity if compared to the themes of teacher one. Themes such as ... The content selected and the vocabulary load were level appropriate, but impractical in terms of stimulating new themes, critical thinking and problem solving skills. Furthermore, there were no links between previous and newly presented information and the cut between themes created less opportunities for the students to remember or re-use the vocabulary introduced previously. Besides, there was little if any links between the content of the laboratory session and the classroom session.

At the laboratory, the teacher started the lesson through a theme presentation by means of using videos, conversations, or songs. After listening, the teacher leads a discussion with the students through questions, examples and explanations creating various interaction opportunities for students. Hence, the laboratory session is a presentation and theme discussion-based. In the classroom, the teacher provides handouts in which the students worked on activities relevant to the theme. After answering the activity, the students provided their answers with a full discussion of each answer with the teacher in relevance to the theme presented. The teacher guided the discussion through questions and explanations. Besides, the teacher used the white board to write the new words presented and encouraged the students to use dictionaries to find out meanings of difficult words. She also created opportunities for interaction among the students to diversify the expression of ideas relevant to the theme. The use of different vocabulary activities (see the teacher profile) created practice variety from a learning session to another. Overall, the teacher relied on a two sequence teaching method in which presentation and practice were fully emphasized.

Comparing the teacher responses to the questionnaire with her observed teaching method outlines a number of contradictions. First, although the teacher stated that vocabulary teaching is very important, and that her purpose was promoting the vocabulary knowledge of learners, she did not clearly state the objectives nor check their fulfillment by the end of the sessions. In identifying her teaching method, the teacher stated in the questionnaire that she uses a semi-contextualizing method. However, the observation reveals that both de-contextualizing and semi-contextualizing were used. The types of activities selected in the questionnaire were limited to providing definitions, synonyms, antonyms and matching activities, but the observation widened the scope of activities to use speaking activities, sentence completion activities, gap filling activities, and use context to draw meaning activities.

While the teacher claimed that she uses no vocabulary assessment in the questionnaire, the observation showed that the variety of practice activities include many assessment methods such as matching questions, gap filling and sentence completion tests.

\section{Summary of Results and Discussion}

This study investigated the methods of vocabulary teaching that Teachers of English as a foreign language at the English Language and Literature Department at Sétif 2 University use in their classrooms. The aim was to gather the perceptions of teachers towards vocabulary teaching in order to examine their degree of awareness about methods of teaching vocabulary.

The quantitative findings obtained through the questionnaire revealed that teachers' have low perceptions of vocabulary teaching methods. Hence, teachers insisted on the importance of vocabulary in teaching their modules supporting the view of many scholars (Ellis, 1994; Lewis, 1993; Nandy, 1994; Zimmerman, 1997). However, this importance was not sustained by the overall objective of developing the VK of the students that teachers stated behind teaching vocabulary. Indeed, many scholars (McCarthy, 1990; Nagy, 1997; Read, 2000) emphasized that increasing the VK of learners goes fundamentally into the whole process of teaching and education. Furthermore, teachers stated that they teach vocabulary explicitly to meet the requirements of their subject areas. Scholars (Cunningham, 2005; Hiebert \& Kamil, 2005; Nagy, 2005; Skehan, 1998; Stahl, 2005) emphasized the efficiency of explicit vocabulary teaching. However, the findings report a low perception of vocabulary teaching methods and activities. 
The qualitative data obtained from the observation provided concrete data about vocabulary teaching methods in the classroom. The observation results confirmed the teachers' view on the importance of vocabulary for English teaching. However, the three teachers observed used the same method of teaching vocabulary. The discussion theme-based method shaped the practices of the three teachers although the themes selected were different. Furthermore, though the development of the lessons did not go in the same direction, the three teachers focused on explicit discussion of the selected themes. Noticeably, the themes of the first teacher were debatable, varied and selected carefully to create a discussion environment if compared to the themes of the other two teachers. However, the second and third teachers did not dominate the discussions in their classrooms and created opportunities for students' spoken productive vocabulary through practice.

The comparison of the observation findings with the observed teacher's responses to the VTAMQ revealed a lack of awareness about vocabulary teaching methods. The teachers indicated a low perception of teaching methods and selected methods that they were not actually using in their classrooms. They also failed to recognize the types of activities used. Moreover, teachers followed an explicit vocabulary teaching method that emphasized receptive vocabulary during the observation. Yet, their questionnaire responses opted for an explicit instruction emphasizing productive vocabulary.

\section{Conclusion and Recommendations}

This research reported the perception of EFL teachers towards vocabulary teaching methods. The low perceptions obtained via the questionnaire use overlapped with the actual situation of vocabulary teaching in the classroom as revealed by means of the observation. Hence, the findings concluded that teachers are not fully aware of their vocabulary teaching methods. Moreover, the sequencing of lesson stages excluded main stages being practice, production, or both, which affected the overall vocabulary teaching method used. In the light of these findings, teachers need to be aware of vocabulary teaching methods for better teaching performance. The findings obtained from the observation and the questionnaire could provide insights to teachers for reflecting and reviewing their vocabulary teaching methods. Receiving vocabulary positively as an important language sub-skill needs to be strengthened via efficient teaching methodologies. Keeping reflective teaching journals and participating in vocabulary teaching workshops and blogs can raise the awareness of teachers about vocabulary teaching methods. The findings of this study raised further researchable questions about the effect of using specific sequencing of lesson stages- as in the context of this study, on vocabulary learning. Similar research may be conducted with teachers at different teaching settings.

\section{References}

Beck, I. L., McKeown, M. G., \& Omanson, R. C. (1987). The effects and uses of diverse vocabulary instructional techniques. In M. G. McKeown \& M. E. Curtis (Eds.), The nature of vocabulary acquisition (pp. 147-163). Hillsdale, NJ: Erlbaum.

Carter, R. \& McCarthy, M. (1988). Vocabulary and language teaching. Harlow: Longman.

Cunningham, A. (2005). Vocabulary growth through independent reading and reading aloud to children. In E. H. Hiebert \& M. L. Kamil (Eds.), Teaching and learning vocabulary: Bringing research to practice (pp. 45-68). Mahwah, New Jersey: Lawrence Erlbaum Associates.

Dornyei, Z. (2003). Questionnaires in second language research. Mahwah, New Jersey: Lawrence Erlbaum.

Duin, A. H., \& Graves, M. F. (1987). Intensive vocabulary instruction as a prewriting technique. Reading Research Quarterly, 22(3), 331-330. http://dx.doi.org/10.2307/747971

Ellis, N. (1994). Vocabulary acquisition: the implicit ins and outs of explicit cognitive mediation. In N.C. Ellis (Ed), Implicit and Explicit Learning of Languages (pp. 211-282). London: Academic Press.

Ellis, R. (1993). Second language acquisition and the structural syllabus. TESOL Quarterly, 27, 91-113. http://dx.doi.org/10.2307/3586953

Harmer, J. (1993). The practice of English language teaching. Essex: Longman Group UK Limited.

Kamil, M., \& Hiebert, E. (2005). Teaching and learning vocabulary: Perspectives and persistent issues. In E. H. 
Hiebert \& M. L. Kamil (Eds.), Teaching and learning vocabulary: Bringing research to practice (pp. 1-23). Mahwah, NJ: Lawrence Erlbaum.

Laufer, B. (1997). The lexical plight in second language reading: Words you don't know, words you think you know and words you can't guess. In J. Coady \& T. Huckin (Eds.), Second language vocabulary acquisition: A rationale for pedagogy (pp. 20-34). Cambridge University Press.

Laufer, B., \& Paribakht, T. (1998). The relationship between passive and active vocabularies: Effects of language learning context. Language Learning, 48, 365-391. http://dx.doi.org/10.1111/0023-8333.00046

Lessard-Clouston, M. (1996). Vocabulary and the ESL/EFL curriculum. TESL Reporter, 29(2), 21-33.

Lewis, M. (1993). The lexical approach: The state of ELT and the way forward. Hove, England: Language Teaching Publications.

Lewis, M. (1997). Implementing the lexical approach: Putting theory into practice. Hove: Language Teaching Publications.

Malvern, D., Richards, B., Meara, P., \& Milton, J. (2008). Introduction: Special issue on knowledge and use of the lexicon in French as a second language. French Language Studies, 18, 269-276. http://dx.doi.org/10.1017/S095926950800344X

McCarthy, M. J. (1990). Vocabulary. Oxford: Oxford University Press.

Meara, P. (1995). Single subject studies of lexical acquisition. Second Language Research, 11(2), i-iii. http://dx.doi.org/10.1177/026765839501100201

Nagy, W. (1997). On the role of context in first- and second-language vocabulary learning. In N. Schmitt \& M. McCarthy (Eds.), Vocabulary: Description. Acquisition and pedagogy (pp. 64-83). Cambridge: Cambridge University Press.

Nagy, W. (2005). Why vocabulary instruction needs to be long-term and comprehensive. In E. H. Hiebert \& M. L. Kamil (Eds.), Teaching and learning vocabulary: Bringing research to practice (pp. 27-44). Mahwah, NJ: Lawrence Erlbaum.

Nation, P. (2001). Learning vocabulary in another language. Cambridge: Cambridge University Press. http://dx.doi.org/10.1017/CBO9781139524759

Nation, P., \& Newton, J. (1997). Teaching vocabulary. In J. Coady \& T. Huckin (Eds.), Second language vocabulary acquisition (pp. 238-254). Cambridge: Cambridge University Press.

Nattinger, J. R., \& DeCarrico, J. S. (1992). Lexical phrases and language teaching. Oxford: Oxford University Press.

Newton, J. (2001). Options for vocabulary learning through communication tasks. ELT Journal, 55(1), 30-37. http://dx.doi.org/10.1093/elt/55.1.30

Oxford, R., \& Crookall, D. (1990). Vocabulary learning: A critical analysis of techniques. TESL Canada Journal 7, 9-30.

Oxford, R., \& Scarcella, R. (1994). Second language vocabulary learning among adults: state of the art in vocabulary instruction. System, 22(2), 231-243. http://dx.doi.org/10.1016/0346-251X(94)90059-0

Read, J. (2000). Assessing vocabulary. Cambridge: Cambridge University Press. http://dx.doi.org/10.1017/CBO9780511732942

Schank, R. (1999). Dynamic memory revisited. Cambridge: Cambridge University Press. http://dx.doi.org/10.1017/CBO9780511527920

Schmitt, N. (2000) Key concepts in ELT: Lexical chunks. ELT Journal 54(4), 400-401. http://dx.doi.org/10.1093/elt/54.4.400

Schmitt, N. (2001). Vocabulary in language teaching. Cambridge: Cambridge University Press.

Seal, B. D. (1991). Vocabulary learning and teaching. In M. Celce- Murcia (Ed.), Teaching English as a second or foreign language (pp. 296-311). Boston, MA: Heinle \& Heinle.

Sinclair, J. M., \& Renouf, A. (1988). A lexical syllabus for language teaching. In R. Carter \& M. McCarthy (Eds.), Vocabulary and language teaching (pp. 140-160). London: Longman.

Skehan, P. (1998). A cognitive approach to language learning. Oxford: Oxford University Press.

Sökmen, A. J. (1997). Current trends in teaching second language vocabulary. In N. Schmitt \& M. McCarthy (Eds.), Vocabulary: Description, acquisition and pedagogy (pp. 237-257). Cambridge: Cambridge 
University Press.

Stahl, S. (2005). Four problems with teaching word meanings (and what to do to make vocabulary an integral part of instruction). In E. H. Hiebert \& M. L. Kamil (Eds.), Teaching and learning vocabulary: Bringing research to practice (pp. 95-114). Mahwah, New Jersey: Lawrence Erlbaum Associates.

Ur, P. (1996). A course in language teaching. Cambridge: CUP.

Zimmerman, C. B. (1997). Historical trends in second language vocabulary instruction. In J. Coady \& T. Huckin (Eds.), Second language vocabulary acquisition: A rationale for pedagogy (pp. 5-19). Cambridge: Cambridge University Press. 
Bouirane, A. 